\title{
Aspectos gerais do Sars-CoV-2 na saúde reprodutiva feminina: uma revisão narrativa
}

\author{
General aspects of Sars-CoV-2 in female reproductive health: a narrative review
}

Aspectos generales de Sars-CoV-2 en la salud reproductiva femenina: una revisión narrativa

Ana Cláudia Ribeiro Farias ${ }^{1 *}$, Wilian Reis Rosário ${ }^{1}$, Kassyo Lenno Sousa Dantas ${ }^{1}$, Milena da Silva Santos ${ }^{1}$, Camila Pinheiro Santiago Silva ${ }^{1}$, Maria Eduarda Melo Souza ${ }^{1}$, Carlos Henrique França Vieira ${ }^{1}$, Domingos Magno Santos Pereira ${ }^{1}$, Antônio Carlos Melo Lima Filho ${ }^{1}$, Caroline Amélia Gonçalves¹.

\section{RESUMO}

Objetivo: Avaliar os impactos gerais da infecção pelo SARS-CoV-2 na saúde reprodutiva feminina assim como nos procedimentos de reprodução assistida. Revisão bibliográfica: O SARS-CoV-2 surgiu em dezembro de 2019 e se espalhou rapidamente pelo mundo. O vírus adentra a célula-alvo ligando-se a enzima de conversão da angiotensina (ACE) 2, da serina protease transmembranar 2 (TMPRSS2) e 4 (TMPRSS4) e da proteína transmembrana Basigin (BSG) nas células hospedeiras, estando esses presentes nas células do aparelho reprodutor feminino podendo impactar significativamente no desempenho reprodutivo das pacientes acometidas pelo SARS-CoV-2. As sociedades de reprodução se uniram para fornecer recomendações com o intuito de diminuir os riscos de infeção entre os pacientes e profissionais de saúde durante os procedimentos nas clínicas de Embriologia, com protocolos de biossegurança rigorosos. Considerações finais: A pesquisa de mulheres acometidas por SARS-CoV-2 torna-se muito importante, uma vez que o vírus pode impactar no sistema reprodutor feminino, podendo comprometer o ovário, estroma, corpo lúteo, útero, células germinativas e oócitos, pela expressão de ACE2, TMPRSS2 e BSG.

Palavras-chave: Sars-Cov-2, Fertilidade feminina, Reprodução assistida.

\begin{abstract}
Objective: Assess the overall impacts of SARS-CoV-2 infection on female reproductive health as well as on assisted reproduction procedures. Bibliographic review: SARS-CoV-2 appeared in December 2019 and spread rapidly around the world. The virus enters the target cell by binding to the angiotensin converting enzyme (ACE) 2, transmembrane serine protease 2 (TMPRSS2) and 4 (TMPRSS4) and Basigin transmembrane protein (BSG) in host cells, these being present in the cells of the female reproductive system which may significantly impact the reproductive performance of patients affected by SARS-CoV- 2 . Human reproduction societies have come together to provide recommendations in order to reduce the risk of infection among patients and health professionals during procedures at Embryology clinics, with strict biosafety protocols. Final considerations: The research of women affected by SARS-CoV-2 becomes very important, once the virus can impact in the female reproductive system, being able to infect the ovary, stroma, corpus luteum, uterus, germ cells and oocytes, by the expression of ACE2, TMPRSS2 and BSG.
\end{abstract}

Keywords: Sars-Cov-2, Female fertility, Assisted reproduction.

\section{RESUMEN}

Objetivo: Evaluar los impactos generales de la infección por SARS-CoV-2 en la salud reproductiva femenina, así como en los procedimientos de reproducción asistida. Revisión bibliográfica: SARS-CoV-2 apareció en diciembre de 2019 y se extendió rápidamente por todo el mundo. El virus entra en la célula diana uniéndose a la enzima convertidora de angiotensina (ECA) 2, la serina proteasa transmembrana 2

1 Universidade CEUMA (UNICEUMA), Imperatriz - MA. *E-mail: ana57claudia@gmail.com 
(TMPRSS2) y 4 (TMPRSS4) y la proteína transmembrana Basigin (BSG) en las células huésped, que están presentes en las células del sistema reproductor femenino y pueden impactar el desempeño reproductivo de los pacientes afectados por el SARS-CoV-2. Las sociedades de reproducción humana se han unido para brindar recomendaciones con el fin de reducir el riesgo de infección entre pacientes y profesionales de la salud durante los procedimientos en las clínicas de Embriología, con estrictos protocolos de bioseguridad. Consideraciones finales: La investigación de mujeres afectadas por SARS-CoV-2 se vuelve muy importante, uma vez que lo vírus puede impactar em lo sistema reproductor femenino, pudiendo infectar el ovario, estroma, cuerpo lúteo, útero, células germinales y ovocitos, por la expresión de ACE2, TMPRSS2 y BSG.

Palabras clave: Sars-Cov-2, Fertilidad femenina, Reproducción asistida.

\section{INTRODUÇÃO}

A propagação do vírus SARS-CoV-2 se transformou rapidamente em uma grave emergência de saúde, sendo considerada pela Organização Mundial de Saúde (OMS) como uma pandemia de importância global (OMS, 2020). Inicialmente, identificado na cidade de Wuhan como o agente causador de uma pneumonia grave, conhecida como COVID-19, a infecção pelo vírus vem causando também impactos negativos em aspectos socioeconômicos principalmente de países em desenvolvimento e subdesenvolvidos (JOSEPHSON A, et al., 2021).

Assim, até junho de 2021 foram mais de 178 milhões de infecções confirmadas em todo o mundo, sendo no Brasil, mais de 18 milhões de casos. Segundo ainda dados apontados pelo Boletim Epidemiológico liberado e Ministério da Saúde, foram mais de 349 mil mulheres hospitalizadas e cerca de 115 mil óbitos associados à infecção pelo vírus no sexo feminino (BRASIL, 2021b; BRASIL, 2021a).

Sabe-se que o SARS-CoV-2 é um vírus de ácido ribonucleico (RNA) fita simples em sentido positivo, que pode infectar as células-alvo através da interação entre a proteína Spike (S) viral e a enzima conversora de angiotensina 2 (ACE2), presente nas células do hospedeiro. Além disso, há também a necessidade da interação do vírus com a serina protease transmembranar 2 (TMPRSS2) para o priming da proteína $S$ (HOFFMANN, et al., 2020). Desta forma, órgãos com alta expressão de ACE2 e TMPRSS2 em teoria, são os mais suscetíveis à infecção. Assim é possível que exista uma correlação de lesões decorrentes da sua infecção não apenas nos pulmões, mas também em outros tecidos que expressam tais receptores, como 0 coração, rim, trato gastrointestinal e tecido nervoso (ZHANG H, et al., 2020; LI YC, et al., 2020).

Da mesma forma, ressalta-se que além dos órgãos citados, outro possível local de infecção pelo vírus são os tecidos reprodutivos femininos, devido as suas células expressarem genes para esses receptores (SUNGNAK W, et al., 2020). Corroborando com esta ideia, já foi descrito que o SARS-CoV 2 é capaz de invadir as células humanas por meio da ligação da proteína $S$ à proteína transmembrana Basigin (BSG), importante no desenvolvimento normal do folículo e a formação do corpo lúteo (HENAREJOS-CASTILLO I, et al., 2020). Por sua vez, pesquisadores identificaram a presença do receptor BSG em oócitos humanos e trofoectoderma de blastocisto, sendo a BSG também expressa no útero, células germinativas, estroma, células da granulosa do ovário (ESSAHIB W, et al., 2020; MAHDIAN S, et al., 2020).

Desta forma, com base na temática supracitada, a investigação das mulheres acometidas pelo vírus SARS-CoV-2 torna-se relevante, visto que eles podem trazer prejuízos em pequeno, médio ou a longo prazo, tanto na citologia do aparelho reprodutivo no amadurecimento e fertilização de seus gametas. A partir desta ideia, o vírus pode impactar de forma significativa na ovulação, fertilização e implantação embrionária (SHARMA I, et al., 2021).

Fundamentado no exposto, este artigo de revisão busca evidenciar e correlacionar quais são os impactos gerais da infecção pelo SARS-CoV-2 na saúde reprodutiva feminina, e nos procedimentos de reprodução assistida, uma vez que novos procedimentos de biossegurança estão sendo adotadas pelas clínicas de reprodução assistida. Tais procedimentos visam a segurança das pacientes e profissionais, assegurando a qualidade do material biológico e no serviço prestado. 


\section{REVISÃO BIBLIOGRÁFICA}

\section{Material genético do SARS-CoV-2}

Similar ao vírus SARS-CoV e MERS-CoV, o genoma viral do SARS-CoV-2 é composto por aproximadamente 30.000 pares de bases, sendo o seu RNA é semelhante a um RNA mensageiro (RNAm). Tal semelhança acontece por conta da presença de uma metilição na extremidade 5' e pela formação de uma cauda poliadenilada (poli-A) na extremidade 3'. Além disso, o RNA viral possui cerca de seis fases de leitura aberta (ORFs) referente ao coronavírus (RABAAN AA, et al., 2020).

O material genético do vírus se traduz em duas poliproteínas, chamadas de pp1a e pp1ab, que são transformadas em 16 proteínas maduras não estruturais (nsp1 - nsp16, do inglês non-strucutral proteins) por fragmentos de leitura aberta (ORF) 1a e b. Essas proteínas participam de uma função importante na replicação e transcrição do RNA viral (KUMAR S, et al., 2020). Dentro do seu genoma, ainda é possível observar que a região do domínio de ligação ao receptor (RDB do inglês receptor-binding domain) da proteína Spike (S) é a porção mais variável (ZHOU P, et al., 2020).

\section{Estrutura viral do SARS-CoV-2}

Pertencente à família Coronaviridae, o SARS-CoV-2 se assemelha a uma coroa, a sua partícula viral mede entre 60 a $140 \mathrm{~nm}$ de diâmetro e picos que variam de 8 a $12 \mathrm{~nm}$ de comprimento. Com material genético RNA de fita simples de senso positivo (RNA+), possui quatro proteínas estruturais, sendo as principais a glicoproteína de $S$, glicoproteína do envelope $(E)$, proteína de membrana $(M)$ e proteína de nucleocapsídeo (ZENG J, et al., 2020).

A região RBD da proteína $S$ é formada por 6 aminoácidos principais, que tem como função ligar-se aos receptores ACE2 da célula hospedeira, iniciando o processo de invasão viral (ZHOU P, et al., 2020). Além disso, o nucleocapsídeo está altamente envolvido na ligação do material genético viral e a resposta das células hospedeiras a infecção viral; a proteína $M$ é uma proteína estruturada e tem a função de determinar a forma do envelope viral; a proteína $E$ tem a função de produção e maturação do vírus (LI G, et al., 2020; ASTUTI I, et al., 2020) A seguir pode-se observar uma ilustração desenvolvida através da Microsoft Publisher (programa do pacote Microsoft Office). Na figura 1 podem ser vistas as principais proteínas do SARS-CoV-2 de modo esquemático.

Figura 1 - Estrutura viral do SARS-CoV-2.

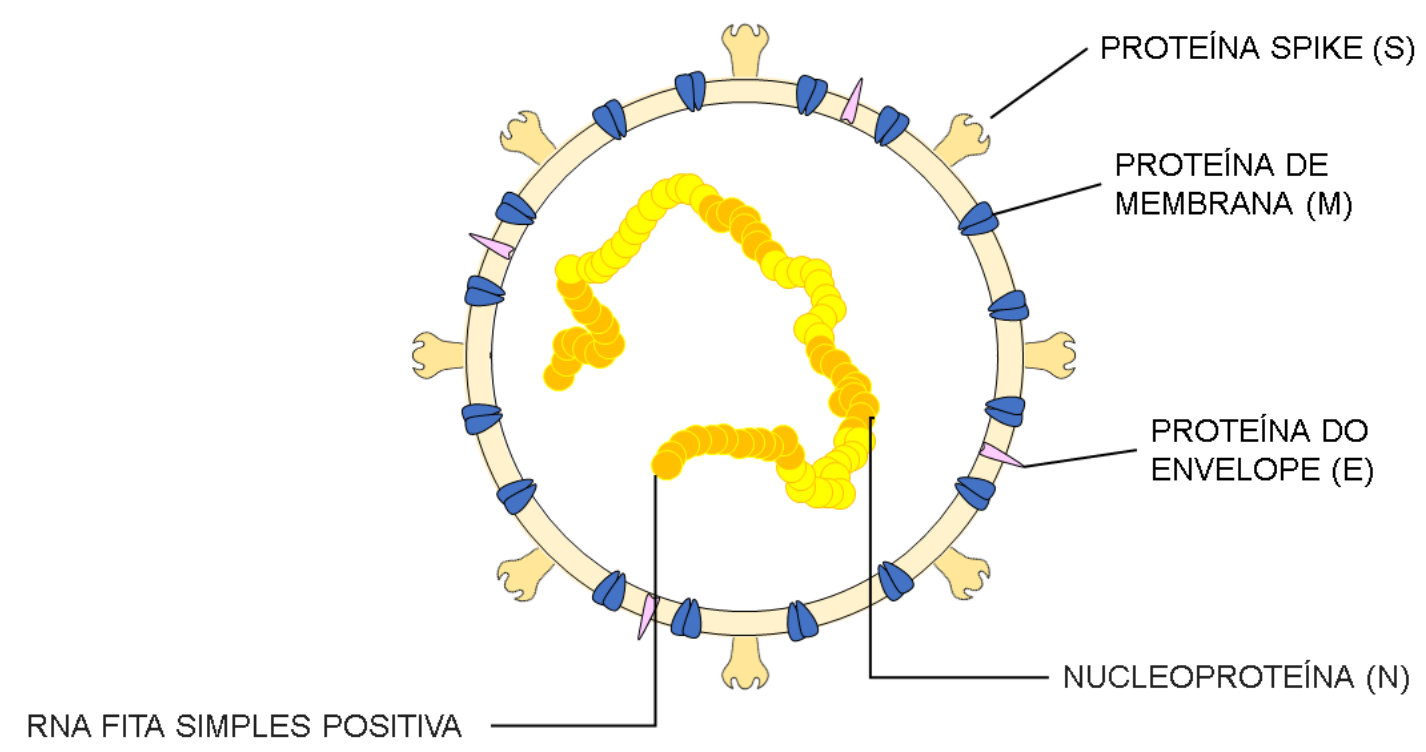

Fonte: Farias ACR, et al., 2021. 


\section{Entrada do vírus nas células hospedeiras}

Sabe-se que para entra e infectar as células hospedeiras, o SARS-CoV-2 depende da proteína S nos receptores celulares e da iniciação da unidade de superfície $S 1$ da proteína $S$, facilitando a ligação viral (HOFFMANN M, et al., 2020). A entrada necessita também da iniciação da proteína $S$ por proteases celulares, afetando a clivagem da proteína $S$ em porções específicas, permitindo a fusão da membrana viral com a membrana da célula hospedeira (LI G, et al., 2020). Além disso, destaca-se ainda que as proteínas $S$ virais são divididas em duas subunidades (S1 e S2), sendo a porção $S 1$ responsável pela interação com o receptor ACE2 no seu domínio RBD, enquanto a porção S2 promove a fusão do envelope viral com a membrana da célula hospedeira (GUO YR, et al., 2020; ZHOU P, et al., 2020; PASTRIAN-SOTO G, 2020).

A ACE2 é um constituinte de grande importância do sistema renina-angiotensina, efetua funções fisiológicas articulando os graus de angiotensina II (Ang II) e Ang- (1-7) molécula responsável pelo aumento da pressão arterial por meio da variação de diferentes caminhos no sistema renina-angiotensinaaldosterona. A expressão do receptor da ACE2 em diversos órgãos é identificada como o principal mecanismo de introdução do coronavírus na corrente sanguínea e nos pulmões, além do envolvimento de outros órgãos, como o sistema reprodutor feminino (GOAD J, et al., 2020; JING Y, et al., 2020).

Desta forma, Guo YR, et al. (2020) afirmam que para que a entrada seja feita com êxito, a proteína $S$ deve ser cortada, uma função concretizada pela da serina protease transmembranar 2 e 4 (TMPRSS2 e TMPPRSS4, respectivamente) e/ou pelas catepsinas B e $L$ atuantes nos endossomos de várias células, contribuindo com a separação entre a porção RBD da subunidade $S 1$ da proteína do vírus com o receptor ACE2. Consequentemente, ocorre a fusão completa da membrana celular com o envelope viral, resultando na entrada do nucleocapsídeo do vírus no citoplasma, posteriormente com a liberação do RNA viral e início do processo de replicação (HOFFMANN M, et al., 2020).

A passagem do vírus também pode acontecer por meio da formação de endossomos (PASTRIAN-SOTO $G, 2020)$. Nessa situação, o vírus dependente da ação das catepsinas $B / L$ ou por fusão direta do envelope com a membrana citoplasmática, processo feito pelo TMPRSS2. Na falta de TMPRSS2, o vírus entra apenas pela formação de endossomos. Em todos os casos, a proteína de pico deve ser clivada para que o processo ocorra (LI G, et al., 2020).

\section{Efeito do SARS-CoV-2 no sistema reprodutor feminino}

Causando impactos socieconomicos, culturais e na saúde humana, a infecção pelo SARS-CoV-2 é umas das principais temáticas atuais em todo o mundo. Com base em seu amplo espectro de sintomas, que variam desde estado febril, perda do olfato e mal-estar geral, à síndrome respiratória aguda (COVID-19), uns dos eventos possíveis e menos ressaltados são os seus efeitos no sistema reprodutor feminino (LI F, et al., 2020). É importante ressaltar que o aparelho reprodutor feminino tem uma importante função no organismo da mulher, é formado principalmente pelas células germinativas, células da granulosa, células foliculares, células ciliadas, células secretoras e etc (SUNGNAK W, et al., 2020).

Como já explorado anteriormente, o vírus necessita da proteína ACE2 para entrar nas células, e da mesma forma da serinas TMPRSS2 e TMPRSS4. Outras proteínas importantes neste processo são as catepsinas B e L (CTSB, CTSL), protease com a previsão de clivar a proteína S, Enzima de clivagem de aminoácidos básicos emparelhados (FURIN) outra protease com a previsão de clivar a proteína S, GTPase 1 (MX1) semelhante à dinamina MX pode regular a infiltração de neutrófilos e ajudar a infecção do vírus através da alteração da proteína $S$ da elastase de neutrófilos. Para a avaliação destas hipóteses, buscaramse artigos onde foram realizadas avaliações da viabilidade destas células em pacientes infectadas com SARS-CoV-2 (GOAD J, et al., 2020., WANG N, et al., 2020).

Tais mecanismos são viáveis graças à expressão de ACE2 pelas células da granulosa, podendo ainda ser encontrado nas células do estroma e em oócitos em ovários de ratos imaturos. Como aliado a esta forma de entrada, a proteína BSG, também conhecido como CD147, apresenta a função de facilitar a infecção das células hospedeiras, sendo necessária para a entrada do vírus devido a sua ligação com proteínas do SARS-CoV-2 (SHARMA I, et al., 2021). 
No sistema reprodutor feminino a BSG esta relacionada a regulação da fertilidade feminina, mas como já supracitado, a sua ligação com o SARS-CoV-2 pode ter um significativo impacto pois a proteína possui a maquinaria molecular para auxiliar a infecção do vírus (VIRANT-KLUN I e STRLE F, 2021). Devido estar expressa no estroma, nas células da granulosa do ovário e útero, a mesma pode servir de porta de entrada para o vírus no sistema reprodutor feminino (LI F, et al., 2021).

Estudos de Henarejos-Castillo I, et al. (2020) mostrou que desde a fase proliferativa até a fase secretora média, particularmente na fase secretora inicial do endométrio tem uma equiparação positiva entre a ACE2 e a idade, o que quer dizer que mulheres com idade mais avançada podem ser mais tendenciosas a ter infecção por SARS-CoV-2.

Associada ainda a ideia da facilitação da entrada do vírus em células reprodutivas femininas, já foram encontrados níveis significativos de RNAm para ACE2 em ovários de mulheres na pós-menopausa e em idade reprodutiva. Corrorobrando com esta ideia, por meio da análise do banco de dados geneCards, foi descoberto que a ACE2 é consideravelmente expressa no ovário (JING Y, et al., 2020; GENECARDS, 2021; BGEE, 2018).

Além disso, Wangner $\mathrm{M}$, et al. (2020) utilizaram o sequenciamento de uma única célula do córtex ovariano, para avaliar a expressão de ACE2 e outros genes em células ovarianas e células do estroma. De acordo com estes estudos (WAGNER M, et al., 2020). Os níveis de RNAm para CTSB e CTSL foram notavelmente expressos em todas as células ovarianas testadas, entretanto, não foram observadas células que co-expressavam ACE2, CTSB, CTSL (WANG N, et al, 2020). Desta forma, na ausência de coexpressão destes marcadores, há necessidade que o vírus entre nas células que expressam ACE2 e TMPRSS2 ou TMPRSS4.

Deste modo, Henarejos-Castillo I, et al. (2020) de acordo com o banco de dados Gene Expression Omnibus, descobriu que diversos genes ligados à infecção do SARS-CoV-2 estão expressos no endométrio ao longo do período mestrual. Os genes CTSL, CTSB, MX1, FURIN, TMPRSS4 e BSG foram expressos em alto grau ao longo do ciclo, TMPRSS2 foi relativamente expresso e ACE2 baixo, sendo este indicativo de que o endométrio pode ser seguro contra a infectividade do vírus. Além disso, a avaliação de acordo com a idade mostrou que ACE2 tem expressão elevada nas fases proliferativas, secretora inicial e secretora média. MX1 e TMPRSS4 foram bastante associados com a idade na fase secretora inicial, CTSL, CTSB e TMPRSS4 foi positivo na fase secretora tardia.

Também foram encontradas elevadas associações negativas para FURIN na fase intermediária e BSG na fase secretora inicial, o que significa que possui uma baixa expressão para infecção. As diferenças de expressão gênica de uma fase para outra e a alteração das próprias proteínas virais durante o ciclo menstrual, faz com que haja um risco de infecção por SARS-CoV-2 (HENAREJOS-CASTILLO I, et al., 2020).

Wang N, et al. (2020) fizeram uma pesquisa fundamentada no mapa de proteínas humanas (HPA) onde mostraram que os transcritos da ECA2 eram relativamente baixos no endométrio. TMPRSS4 e FURIN também tiveram expressão baixa, assim como CTSB, MX1 e BSG. Em contrapartida, eles indicaram também que TMPRSS4, CTSL, CTSB, FURIN, MX1 e BSG foram expressos em todas as fases do endométrio. Desta forma, os pesquisadores sugeriram que o SARS-CoV-2 possivelmente não causaria inflamação significativa do miométrio e em outras células do sistema reprodutor.

De acordo com o trabalho publicado de Stanley KE, et al. (2020) utilizando a fonte de dados do Human Protein Altas e Human Proteome MAP foi observado que dos sete tipos de células ovarianas, a expressão de ACE2 e TMPRSS2 é limitada as células germinativas. Nos oócitos há uma expressão baixa de ACE2, enquanto que TMPRSS2 a expressão é de acordo com a maturidade do oócito. A seguir pode-se observar uma ilustração desenvolvida através do Software Web CoreIDRAW (programa do pacote Microsoft Office). $\mathrm{Na}$ figura 2 podem ser vistas a capacidade de infecção do SARS-CoV-2 no perfil reprodutivo feminino, evidenciando os fatores do hospedeiro envolvidos. 
Figura 2 - Infecção por SARS-CoV-2 no sistema reprodutor feminino.

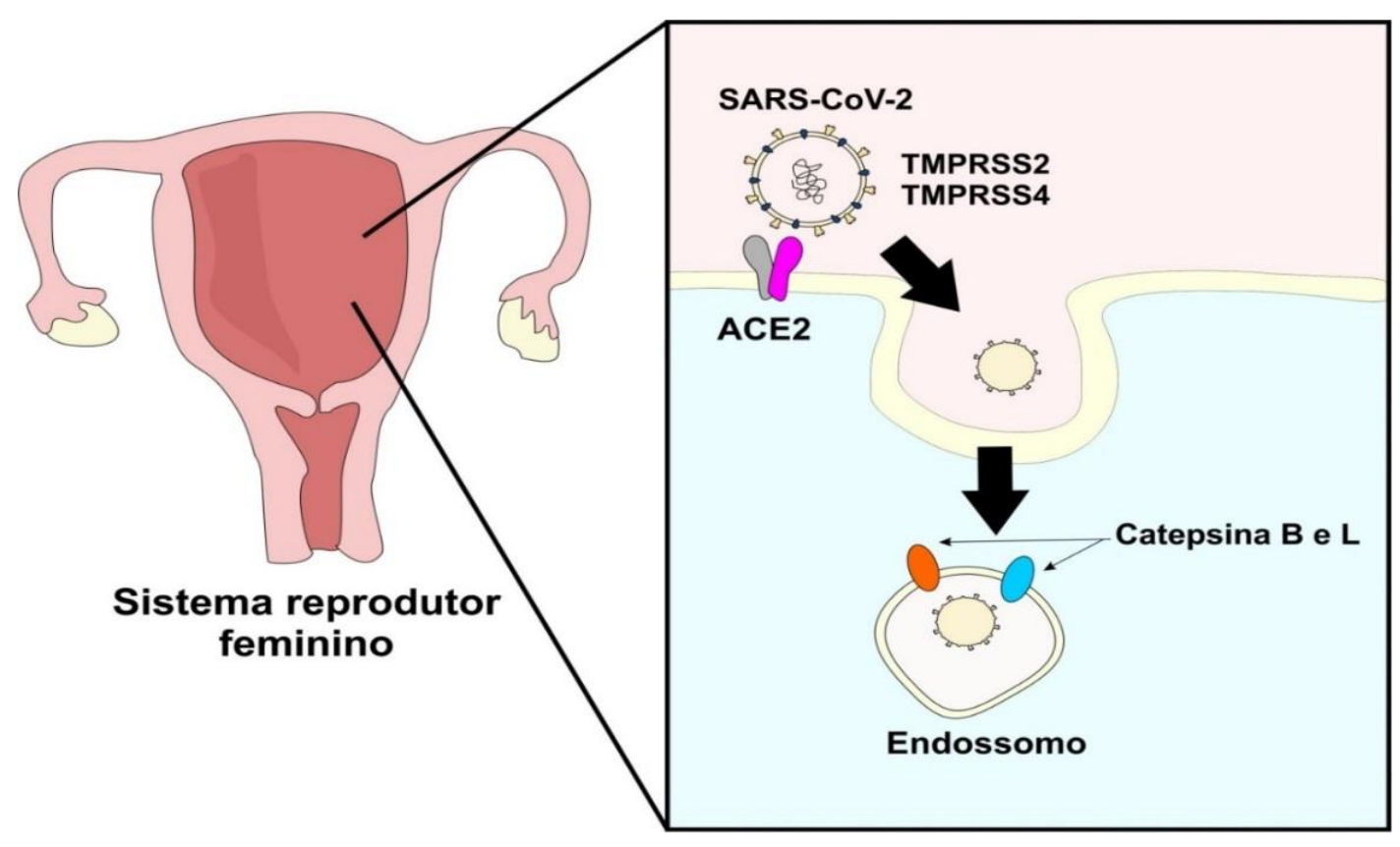

Fonte: Farias ACR, et al., 2021.

\section{Técnicas de reprodução humana assistida na pandemia do COVID-19}

Estima-se que sejam realizados mais de 43 mil ciclos de fertilização in vitro anualmente no Brasil (ANVISA, 2020). Normalmente, a avaliação da fertilidade feminina se dá em clínicas de fertilização especializadas, por meio de exames como a ultrassonagrafia para contagem de folículos antrais e dosagens hormonais do hormônio folículo-estimulante (FSH), Inibina $\mathrm{B}$ e do hormônio Anti-Mulleriana $(\mathrm{AMH})$. $\mathrm{Na}$ mesma, são avaliadas a reserva ovariana, dados esses extremamente importantes para propor o melhor tratamento de infertilidade (FRITZ R e JINDAL S, 2018).

Tratando-se do contexto da pandemia, destaca-se que tais avaliações são imprenscideveis para garantir a segurança das pacientes, garantidno a avaliação eficaz da fertilidade. De acordo com o estudo de Li R, et al. (2020), existem vias pelas quais o vírus pode atingir a fertilidade feminina afetando as células da granulosa e o tecido ovariano, reduzindo a qualidade dos oócitos e função ovariana por meio do dano direto às células endometriais e epiteliais.

Contrapondo esta ideia, de acordo com o trabalho de Barragan M, et al. (2021), os oócitos isolados de mulheres positivas para o vírus não foram suscetíveis a infecção por SARS-CoV-2, mesmo expressando os genes ACE2, TMPRSS2, Catepsina L (CTSL) e BSG. Neste mesmo estudo observou-se que o RNA viral não foi detectável em todos os 16 oócitos testados. Com base nestas pesquisas iniciais, destaca-se a necessidade de mais estudos que visem diretamente o entendimento de novas vias de entrada do vírus nas células reprodutivas femininas.

Neste mesmo espectro, a pandemia do COVID-19 além de apresentar riscos infecciosos ao sistema reprodutor feminino também forçou medidas preventivas específicas às clínicas de embriologia humana para diminuir o risco de infecção durante os procedimentos de tecnologia de reprodução assistida (ART) (BARRAGAN M, et al., 2021).

Como exemplo deste fato, as Sociedades Americana de Medicina Reprodutiva (ASRM), Sociedade Europeia de Reprodução Humana e Embriologia (ESHRE), Sociedade Brasileira de Reprodução Assistida (SBRA) e a Federação Internacional de Sociedades de Fertilidade (IFFS) se uniram em uma força tarefa para fornecer a importância de cuidados reprodutivos constantes durante a pandemia. Foi preconizado que funcionários deveriam receber treinamento com protocolos específicos para evitar infecção pelo vírus 
SARS-CoV-2, por meio do uso obrigatório de máscaras pelos pacientes e funcionários das clínicas, além do distanciamento físico em áreas de triagem, recepção e laboratório, como também antissepsia de superfícies em áreas já em uso das clínicas e lavagem frequente das mãos (ALTERI A, et al., 2020).

Além disso, foi ainda recomendado alterações na avaliação e tratamento de infertilidade para proteção de pacientes e funcionários, com divisão da equipe do laboratório em dias alternados, e sempre que possível, fazer o uso de telemedicina (GEMMELL LC, et al., 2020).

Assim, visando garantir a segurança de tecidos e células processados, pacientes e profissionais, as técnicas de reprodução humana assistida tem como base a criopreservação de oócitos para evitar contaminação cruzada, o uso de dispositivos fechados de alta segurança, além das boas práticas clínicas e laboratoriais de biossegurança contra a contaminação viral em qualquer nível (PORCU E, et al., 2021, SPARKS AE e KRESOWIK JD, 2021). Já é bem estabelecido que a contaminação cruzada ao longo do crioarmazenamento pode acontecer por meio do tipo de dispositivo usado, aberto ou fechado. No dispositivo criossistema fechado de alta segurança com canudos selados, não tem exposição direta do material reprodutivo no LN2, diminuindo o risco de contaminação cruzada (SHAPIRO, et al., 2020).

Alguns embriologistas apoiam a ideia de colocar todas as amostras criopreservadas em tanques de quarentena, até que sejam realizados testes confirmatórios para a ausência viral. Não sendo detectado o vírus, os óvulos são colocados nos tanques de armazenamento principal. Ao que tudo indica, a COVID-19 poderá fazer parte das nossas vidas em tempos futuros, requerendo mudanças dos protocolos de segurança para seguridade dos pacientes e profissionais do laboratório, o tratamento de fertilidade é um serviço essencial que pode ser executado com responsabilidade e segurança durante a pandemia (POMEROY KO e SCHIEWE MC, 2020).

\section{CONSIDERAÇÕES FINAIS}

O mundo encontra-se ainda num processo de adaptação aos efeitos negativos acarretados pela pandemia do SARS-CoV-2. Destacam-se város sintomas relacionados à esta infecção viral, entretanto o impacto no perfil reprodutivo feminino ainda não é efetivamente ressaltando. Assim, o SARS-CoV-2 podendo comprometer o ovário, útero, células germinativas, corpo lúteo, estroma, blastocisto e oócitos por meio da expressão de ACE2, TMPRSS2 e BSG nestas células. Além disso, pode afetar significativamente as funções reprodutivas femininas na ovulação, fertilização e implantação embrionária, sem contar no risco de contaminações do vírus em oócitos durante a manipulação na reprodução assistida. Por este motivo a investigação a fundo dessas mulheres afetadas pelo vírus torna-se consideravelmente importante, visto que pode impactar na citologia do seu aparelho reprodutivo. Da mesma forma, as clínicas especializadas em saúde reprodutiva feminina têm se adaptado a nova realidade da pandemia, buscando realizar suas atividades garantindo a segurança dos pacientes, amostras coletadas e profissionais da área.

\section{REFERÊNCIAS}

1. ALTERI A, et al. Cryopreservation in reproductive medicine during the COVID-19 pandemic: rethinking policies and European safety regulations. Human Reproduction, 2020; 35 (12): 2650-2657.

2. ANVISA. Agência Nacional de Vigilância Sanitária. Relatório sobre produção nacional de embriões. 2020. Disponível em: https://www.gov.br/anvisa/pt-br/assuntos/noticias-anvisa/2020/divulgado-relatorio-sobre-producao-nacional-deembrioes. Acessado em 11 de junho de 2021.

3. ASTUTI I, et al. Severe Acute Respiratory Syndrome Coronavirus 2 (SARS-CoV-2): An overview of viral structure and host response. Diabetes \& Metabolic Syndrome: Clinical Research \& Reviews, 2020; 14 (4): 407-412.

4. BARRAGAN M, et al. Undetectable viral RNA in oocytes from SARS-CoV-2 positive women. Human Reproduction, $2021 ; 36$ (2): 390-394.

5. BGEE. 2018. Disponível em: https://bgee.org/?page=gene\&gene_id=ENSG00000130234. Acessado em 12 de março de 2021.

6. BRASIL. Manual do Ministério da Saúde 2021. Boletim Epidemiológico. Disponível em: https://www.gov.br/saude/ptbr/media/pdf/2021/junho/25/68_boletim_epidemiologico_covid.pdf. Acessado em 28 de junho de 2021.

7. BRASIL. Manual do Ministério da Saúde 2021. Disponível em: https://qsprod.saude.gov.br/extensions/covid19_html/covid-19_html.html. Acessado em 28 de junho de 2021. 
8. ESSAHIB W, et al. SARS-CoV-2 host receptors ACE2 and CD147 (BSG) are present on human oocytes and blastocysts. Journal of Assisted Reproduction and Genetics, 2020; 37 (11): 2657-2660.

9. FRITZ R, JINDAL S. Reproductive aging and elective fertility preservation. Journal of ovarian research, $2018 ; 11$ (1): 1-8.

10. GEMMELL LC, et al. Considerations on the restriction of Assisted Reproductive Technology (ART) due to COVID-19. In: Seminars in Perinatology. WB Saunders, 2020; 7 (7): 151288.

11. GENECARDS. 2021. The Human Gene Database. Disponível em: https://www.genecards.org/cgibin/carddisp.pl?gene=ACE2\#protein_expression. Acessado em 12 de março de 2021.

12. GOAD J, et al. Female reproductive tract has low concentration of SARS-CoV2 receptors. Plos one, $2020 ; 15$ (12): e0243959.

13. GUO YR, et al. The origin, transmission and clinical therapies on coronavirus disease 2019 (COVID-19) outbreak-an update on the status. Military Medical Research, 2020; 7 (1): 1-10.

14. HENAREJOS-CASTILLO I, et al. SARS-CoV-2 infection risk assessment in the endometrium: viral infection-related gene expression across the menstrual cycle. Fertility and sterility, 2020; 114 (2): 223-232.

15. HOFFMANN M, et al. SARS-CoV-2 cell entry depends on ACE2 and TMPRSS2 and is blocked by a clinically proven protease inhibitor. Cell, 2020; 181 (2): 271-280.

16. JING Y, et al. Potential influence of COVID-19/ACE2 on the female reproductive system. Molecular human reproduction, 2020; $26(6): 367-373$.

17. JOSEPHSON A, et al. Socioeconomic impacts of COVID-19 in low-income countries. Nature Human Behaviour, 2021;5: 557-565.

18. KUMAR S, et al. Structural, glycosylation and antigenic variation between 2019 novel coronavirus (2019-nCoV) and SARS coronavirus (SARS-CoV). Virusdisease, 2020; 31 (1): 13-21.

19. LI F, et al. Impact of COVID-19 on female fertility: a systematic review and meta-analysis protocol. BMJ open, 2021; 11 (2): e045524.

20. LI G, et al. Coronavirus infections and immune responses. Journal of medical virology, 2020; 92 (4): 424-432.

21. LI R, et al. Potential risks of SARS-Cov-2 infection on reproductive health. Reproductive biomedicine online, $2020 ; 41$ (1): 89-95.

22. LI YC, et al. The neuroinvasive potential of SARS-CoV2 may play a role in the respiratory failure of COVID-19 patients. Journal of medical virology, 2020; 92 (6): 552-555.

23. MAHDIAN S, et al. COVID-19 mediated by basigin can affect male and female fertility. International journal of fertility \& sterility, 2020; $14(3): 262$.

24. PASTRIAN-SOTO G. Bases genéticas y moleculares del COVID-19 (SARS-CoV-2). Mecanismos de patogénesis y de respuesta inmune. International journal of odontostomatology, 2020; 14 (3): 331-337.

25. POMEROY KO, SCHIEWE MC. Cryopreservation and IVF in the time of Covid-19: what is the best good tissue practice (GTP)?. Journal of assisted reproduction and genetics, 2020; 37 (10): 2393-2398.

26. PORCU E, et al. High-security closed devices are efficient and safe to protect human oocytes from potential risk of viral contamination during vitrification and storage especially in the COVID-19 pandemic. Journal of Assisted Reproduction and Genetics, 2021; 38 (3): 681-688.

27. RABAAN AA, et al. SARS-CoV-2, SARS-CoV, and MERS-COV: a comparative overview. Infez Med, 2020 ; 28 (2): 174-184.

28. SHARMA I, et al. SARS-CoV-2 and the reproductive system: known and the unknown...!. Middle East Fertility Society Journal, 2021; $26(1): 1-9$.

29. SPARKS AE, KRESOWIK JD. Infection precautions for SARS-CoV-2 in assisted reproduction centers-dodging an invisible bullet. Fertility and Sterility,2021; 115 (4): 831-839.

30. STANLEY KE, et al. Coronavirus disease-19 and fertility: viral host entry protein expression in male and female reproductive tissues. Fertility and sterility,2020; 114 (1): 33-43.

31. SUNGNAK W, et al. SARS-CoV-2 entry factors are highly expressed in nasal epithelial cells together with innate immune genes. Nature medicine, 2020; 26 (5): 681-687.

32. VIRANT-KLUN I, STRLE F. Human Oocytes Express Both ACE2 and BSG Genes and Corresponding Proteins: Is SARS-CoV-2 Infection Possible?. Stem cell reviews and reports, 2021; 1-7.

33. WAGNER M, et al. Single-cell analysis of human ovarian cortex identifies distinct cell populations but no oogonial stem cells. Nature communications, 2020; 11 (1): 1-15.

34. WANG N, et al. Effect of severe acute respiratory syndrome coronavirus-2 (SARS-CoV-2) on reproductive system. Stem Cell Research, 2021; 52: 102189.

35. OMS. Organização Mundial da Saúde. Guia de atenção a saúde. 2020 . Disponível em: https://www.who.int/dg/speeches/detail/who-director-general-s-opening-remarks-at-the-media-briefing-on-covid-19--11-march-2020. Acessado em 11 de março de 2021.

36. ZHANG H, et al. The digestive system is a potential route of 2019-nCov infection: a bioinformatics analysis based on single-cell transcriptomes. BioRxiv, 2020.

37. ZHENG J. SARS-CoV-2: an emerging coronavirus that causes a global threat. International journal of biological sciences, 2020; 16 (10): 1678.

38. ZHOU P, et al. A pneumonia outbreak associated with a new coronavirus of probable bat origin. Nature, 2020; 579 (7798): 270-273. 